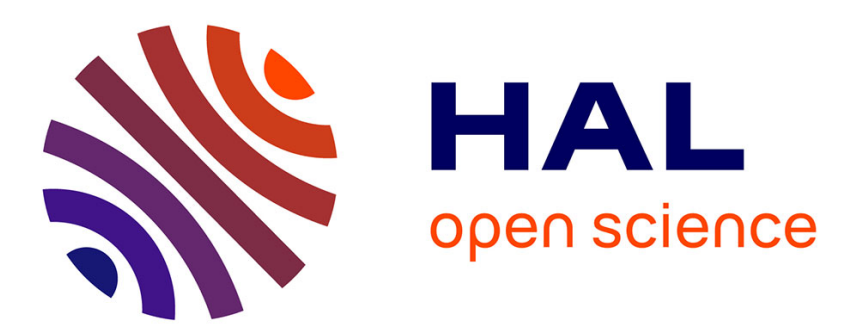

\title{
Treatment-Induced Cardiotoxicity in Breast Cancer: A Review of the Interest of Practicing a Physical Activity
}

Angeline Ginzac, Judith Passildas, Emilie Gadéa, Catherine Abrial, Ioana

Molnar, Romain Trésorier, Martine M. Duclos, Emilie E. Thivat, Xavier Durando

\section{To cite this version:}

Angeline Ginzac, Judith Passildas, Emilie Gadéa, Catherine Abrial, Ioana Molnar, et al.. TreatmentInduced Cardiotoxicity in Breast Cancer: A Review of the Interest of Practicing a Physical Activity. Oncology, 2019, 96 (5), pp.223-234. 10.1159/000499383 . hal-02355131

\section{HAL Id: hal-02355131 https://hal.science/hal-02355131}

Submitted on 8 Nov 2019

HAL is a multi-disciplinary open access archive for the deposit and dissemination of scientific research documents, whether they are published or not. The documents may come from teaching and research institutions in France or abroad, or from public or private research centers.
L'archive ouverte pluridisciplinaire HAL, est destinée au dépôt et à la diffusion de documents scientifiques de niveau recherche, publiés ou non, émanant des établissements d'enseignement et de recherche français ou étrangers, des laboratoires publics ou privés. 
Angeline GINZAC ${ }^{1 *}$, Judith PASSILDAS ${ }^{1}$, Emilie GADEA $^{2}$, Catherine ABRIAL ${ }^{1}$, Ioana MOLNAR ${ }^{1}$,

Romain TRESORIER ${ }^{3}$, Martine DUCLOS ${ }^{4,5}$, Emilie THIVAT $^{1}$, Xavier DURANDO $^{1}$

6

$7 \quad{ }^{1}$ Université Clermont Auvergne, Centre Jean Perrin, INSERM, U1240 Imagerie Moléculaire et

8 Stratégies Théranostiques, Clermont-Ferrand, France

$9 \quad{ }^{2}$ Centre Hospitalier Emile Roux, Le Puy en Velay, France

${ }^{3}$ Centre Jean Perrin, Clermont-Ferrand, FR-63000, France

${ }^{4}$ INRA, UMR 1019, UNH, CRNH Auvergne, Clermont-Ferrand, France

${ }^{5}$ Centre Hospitalier Universitaire Clermont-Ferrand, Service de Médecine du Sport et des

Explorations Fonctionnelles, CRNH, INRA, Université Clermont Auvergne, Clermont-Ferrand,

France

CRNH : Centre de Recherche en Nutrition Humaine; INRA: Institut National de la Recherche Agronomique ; INSERM : Institut National de la Santé et de la Recherche Médicale ; UNH : Unité de

Nutrition Humaine ; UMR : Unité Mixte de Recherche

Short title: Physical activity practice during breast cancer treatment

*Corresponding author:

Angeline GINZAC

Centre Jean Perrin

Division de Recherche Clinique

58, rue Montalembert

CLERMONT-FERRAND Cedex 1, Puy-de-Dôme, 63011, France

Tel: 0463663337

Fax: 0473278029

Email: angeline.ginzac@clermont.unicancer.fr

Keywords: HER2-positive breast cancer, cardiotoxicity, anthracycline, trastuzumab, physical activity 
Physical activity is known to prevent cancer occurrence and to decrease the risk of breast cancer. At diagnosis of breast cancer, fewer than half of the patients reach the international recommendation for physical activity. However, breast cancer patients, and particularly HER2+ breast cancer patients, are exposed to treatment-induced cardiotoxicity because of a side effect of two molecules used in standard therapy to treat these tumors: anthracycline and trastuzumab. Cardiotoxicity can sometimes lead to the treatment being discontinued and even to the development of cardiovascular diseases. Exercise is known to protect the cardiovascular system in the healthy population. Consequently, being physically active during treatment appears as a way to prevent the negative impact of cancer treatment on the heart in this population. In particular, aerobic exercising could provide a protective effect against treatment-induced cardiotoxicity.

A supervised physical activity program seems to be the best way for breast cancer patients to be active during their period of treatment. However, there is very little information available to patients, and in particular a lack of guidelines, on exercising. Interventional trials that have been conducted on this topic are very heterogeneous and no standard recommendations have been made available for cancer patients thus far. An effective physical activity program needs to take each patient's barriers and motivations into account in order to encourage the practice of physical activity throughout treatment. To ensure the success of the program, it is essential to facilitate adherence and especially to maintain motivation. Further studies are needed to determine what practice guidelines oncologists should give their patients. 6 


\section{INTRODUCTION}

Physical inactivity is the fourth mortality risk worldwide [1]. Regardless of the level of physical activity, reducing sedentary time decreases mortality, and also the risk of developing cardiovascular diseases, type 2 diabetes, obesity and certain cancers [2]. In 2010, the World Health Organization (WHO) issued international physical activity recommendations for the healthy population, by age group [3]. Over the following years, these recommendations were extended to breast cancer patients through different frameworks and by different authorities, for example, the Plan Cancer in France [4] and the American Cancer Society [5,6].

The link between high body mass index (BMI) at breast cancer diagnosis and poor prognosis has been well established, and highlights the importance of being physically active $[7,8]$. Physical activity from diagnosis has become a routine recommendation in breast cancer treatment, especially because of its many benefits on quality-of-life $[9,10]$. Physical activity also improves survival rates. Indeed, a metaanalysis has shown that being active after diagnosis is linked to a $34 \%$ reduction in breast cancer deaths, a $41 \%$ reduction in deaths from all causes and a $24 \%$ reduction in disease recurrence [11]. Another meta-analysis evaluating 5- and 10-year survival rates showed that the higher the level of physical activity, the better were the survival rates [12]. Indeed, the 5-year survival rate was $97 \%$ for patients who engaged in 3 to 9 or more metabolic equivalent task (MET) hours per week, and $93 \%$ for those who engaged in fewer than 3 MET-h/weeks. The 10-year survival rate of patients who engaged in 9 or more MET-h/week was $92 \%$, whereas for patients engaging in 3 to $8.9 \mathrm{MET}-\mathrm{h} /$ week it was 89 $\%$, and $86 \%$ for those who practiced for fewer than 3 MET-h/week. However, at diagnosis, the majority of patients are insufficiently active [13-15] and maintaining an adequate level of physical activity during treatment can be difficult on account of the numerous barriers encountered by patients. The most frequent barriers identified over the last decades are treatment side effects and the management of everyday routine activities. In addition to improving the outcomes of cancer, physical activity could limit some of the toxicity of anticancer treatments. There is strong evidence that meeting the international physical activity recommendation (i.e. 150 to 300 minutes of moderate-intensity or 75 to 150 minutes of vigorous-intensity aerobic activity on a weekly basis) reduces the incidence and recurrence of cardiometabolic disease [16,17]. It can thus be hypothesized that patients who develop 
treatment-induced cardiotoxicity could draw benefit from a physical activity intervention.

In order to promote physical activity during treatment, interventional programs are offered to patients. Since 2010, the literature on this topic has been developing, and the number of trials involving physical activity interventions has multiplied. Nevertheless, the question arises as to what is the optimal program, particularly in terms of duration, type of exercise or intensity.

The aim of this review was to explore treatment-induced cardiotoxicity and identify the interest, barriers and facilitators of physical activity practice during treatment in order to mitigate cardiac dysfunction.

\section{BREAST CANCER AND CARDIOTOXICITY}

\section{Anthracycline-induced cardiotoxicity}

Anthracyclines belong to the standard chemotherapy treatment for early breast cancer. Nevertheless, one limitation of this treatment is that it can cause cumulative, dose-dependent cardiac damage, mainly cardiomyopathy and heart failure $[18,19]$.

Patients treated with anthracycline-based chemotherapy are five times more at risk of developing cardiotoxicity than those treated without anthracycline [20]. Some meta-analyses have also shown that the risk of severe cardiotoxicity is higher in patients under anthracycline-based chemotherapy than among those treated with taxanes without anthracycline [21,22]. Cardiotoxicity is defined by a left ventricular ejection fraction (LVEF) $<50 \%$ or a decrease of $10 \%$ in the LVEF compared to baseline [23-26]. It is the first cause of heart failure among women and is responsible for $15-20 \%$ of cases of treatment discontinuation [27].

Two main hypotheses have been put forward to explain the potential mechanisms implicated in anthracycline-induced cardiotoxicity. Some authors have suggested that the reactive oxygen species (ROS) generated by anthracycline treatment cause damage to the DNA and changes in protein and lipid levels, ultimately leading to cardiomyocyte death [28-30]. It has also been shown that doxorubicin-induced cardiotoxicity is linked to the activation of p53 and the apoptotic pathway, leading to a loss of myocardia mass, which contributes to cardiotoxicity [31]. 


\section{Trastuzumab-induced cardiotoxicity}

Approximately $20 \%$ of breast cancer patients overexpress the human epidermal growth factor receptor 2 (HER2) [32]. This characteristic of the tumour has been associated with poorer disease-free and overall survival $[32,33]$. One of the standard treatments for this specific cancer is a targeted therapy, trastuzumab $\left(\right.$ Herceptin $\left.^{\circledR}\right)$, which can be administered alone [23,34] or in combination with chemotherapy [35,36]. Trastuzumab is a recombinant humanized monoclonal anti-body that binds selectively to subdomain IV of the extracellular ErbB2 domain, which downregulates HER2 expression [37]. Adjuvant treatment with trastuzumab reduces by half the rate of recurrence and by one third the mortality rate [38].

It is estimated that $1 \%$ to $4 \%$ of patients treated with trastuzumab develop heart failure $[39,40]$ and nearly $10 \%$ have asymptomatic LVEF reduction [35,41]. The cumulate incidence rate for major cardiac events has been estimated at $6.6 \%$ for sequential therapy (anthracycline and trastuzumab) and $5.1 \%$ for trastuzumab alone [42]. A meta-analysis has shown that patients treated with trastuzumab were about five times more at risk of developing congestive heart failure in early breast cancer compared to patients not treated with this targeted therapy [43]. Nevertheless, if trastuzumab is discontinued at the time of the first cardiac symptoms, the damage can be reversible [44].

It can be hypothesized that trastuzumab-induced cardiotoxicity is linked to antibody-dependent cellular cytotoxicity (ADCC), leading to an immune-mediated destruction of cardiomyocytes or to a disruption of HER2 signalling, which is essential for myocardial contractility, see for example $[44,45]$. It is also important to note that HER2, the target of trastuzumab, is expressed in adult cardiomyocytes and is implicated in cardiomyocyte development [45-49]. When trastuzumab blocks HER2 signalling, it prevents the repair mechanisms in cardiomyocytes [50].

\section{Cardiotoxicity associated with anthracyclines and trastuzumab treatment}

When trastuzumab and anthracycline-based chemotherapy are associated, the incidence of cardiotoxicity is $27 \%$ against $13 \%$ when trastuzumab is associated with paclitaxel [51]. More generally, the risk of cardiac failure is higher when trastuzumab is administered after anthracyclinebased chemotherapy than after non-anthracycline chemotherapy [22]. Patients treated with 
trastuzumab and chemotherapy are twice as likely to develop heart failure or LVEF decrease [52]. Cardiotoxicity can occur acutely but it can also lead to cardiovascular disease development in the long term. A retrospective study compared the incidence of cardiotoxicity in the five years following treatment associating anthracycline and trastuzumab or anthracycline alone. Among the $29.6 \%$ of the patients treated with anthracyclines alone, cardiotoxicity at five years involved $4.3 \%$, while for the 3.5 $\%$ of population who received an association of the two drugs, the proportion was $20.1 \%$, more than 4.5 times greater [53].

Today, new targeted anti-HER2 therapies are available, such as pertuzumab, trastuzumab emtansine (T-DM1), lapatinib, neratinib and afatinib, but they do not have an indication for early breast cancer. A study was conducted to determine the cardiac tolerance of pertuzumab. The TRYPHAENA study assessed cardiac tolerance of the concomitant or sequential addition of pertuzumab and trastuzumab to docetaxel with or without anthracycline in neoadjuvant treatment [54]. The results did not show an increased incidence of cardiac dysfunction. However, more data is needed to confirm the results of this study.

A recent literature review concluded that the cardiac impact of these novel drugs was lower than that of trastuzumab, and they mainly led to an asymptomatic decrease of the LVEF [55]. The mechanisms responsible for the lower cardiotoxicity of these novel drugs are still not completely understood. However, lapatinib is known to activate the adenosine monophosphate kinase (AMPK) pathway, which could protect heart cells against tumor necrosis factor alpha (TNF- $\alpha$ )-induced cell death by inhibiting its stimulation [45].

II. Physical aCtivity to PRevent treatment-Related CARdiotoxicity in BREAST CANCER

\section{Benefits of being physically active for breast cancer patients}

The amount of moderate-to-vigorous physical activity is inversely associated with cardiovascular mortality, and the incidence of cardiovascular disease, stroke and heart failure [16]. Physical activity is also a cornerstone in cardiometabolic chronic diseases such as diabetes or high blood pressure. Among 
healthy subjects, regular physical activity reduces the incidence of cardiac events such as hypertension or coronary heart disease [1]. In addition, among breast cancer patients, physical activity can to some extent improve cardiopulmonary function (increased LVEF, improved heart rate and systolic blood pressure, etc.) [56-66], suggesting that physical activity could prevent some of the potential negative effects of treatment-related cardiotoxicity in HER2+ breast cancer subtypes.

A recent literature review highlighted the interest in implementing an exercise intervention program in the population at risk for cardiotoxicity [67], as is the case with HER2+ breast cancer patients, especially because breast cancer patients can also have pre-existing comorbidities, such as diabetes and hypertension, that predispose them to cardiotoxicity $[67,68]$. The mechanisms explaining the benefit of physical activity on cardiovascular function are still not clearly known. A preclinical study conducted on a murine model showed that physical exercising for 5 consecutive days protected the cardiomyocyte mitochondria from the oxidative damage and dysfunction induced by doxorubicin [69]. Indeed, the authors found that in physical exercising conditions, there was a reduction in doxorubicininduced ROS release from the cardiac mitochondria. In addition, aerobic training induced endogenous antioxidant mechanisms that protect the heart against ROS [70]. A study conducted on 2973 nonmetastatic breast cancer patients assessed the relationship between exposure to physical exercise and cardiovascular events [71]. The results, with a median follow-up of 8.6 years, showed a reduction of $23 \%$ in the risk of cardiovascular events for patients that followed physical activity recommendations (i.e. $\geq 9$ MET-h/week.) after the end of their treatment ( $\geq 9$ MET-h/week) compared to those who did not follow the recommendations.

\section{Physical activity interventions improving cardiopulmonary capacities}

Haykowsky et al. were the first to specifically study the impact of physical activity on trastuzumabinduced cardiotoxicity. They conducted a trial on 17 HER2+ breast cancer patients. A supervised physical activity intervention took place in the course of the first 4 months of trastuzumab administration. The intervention was composed of 3 aerobic sessions of 30 to 60 minutes per week on 
an electrically braked cycle ergometer at 60 to $90 \%$ of the oxygen peak consumption $\left(\mathrm{VO}_{2 \text { peak }}\right)$. The

results of the trial concluded that although the aerobic activity took place during the chemotherapy,

207

208

209

210

211

212

213

214

215

216

217

218 trastuzumab induced left ventricular cavity dilation and a significant decrease in the ventricular ejection fraction [72]. Nevertheless, according to the authors, the relatively low program adherence (59 \%) could explain the absence of a cardioprotective effect of physical activity. Indeed, they highlighted the fact that exercise adherence was predictive of change in peak oxygen consumption and that patients need to attend $\geq 55 \%$ of the prescribed sessions to derive any benefit on cardiopulmonary function. Other studies assessed the effect of physical activity interventions during treatment on the cardiovascular system and cardiorespiratory function among non-HER2+ breast cancer patients (Table 1). The studies were conducted at different moments in treatment: during adjuvant chemotherapy [73,74], during other adjuvant treatments [65-70], or after the end of breast cancer treatment [59]. Rates of adherence to the program were higher than in Haykowsky's study, ranging from $66 \%$ to 98.4 $\%$, and an improvement in cardiopulmonary function was rapidly observed after the physical activity program was started. For example, after 8 or 12 weeks of an aerobic exercise intervention, an increase in the $\mathrm{VO}_{2 \text { peak }}$ and a decrease in systolic blood pressure were observed $[63,66]$. Furthermore, patients following a 12-week aerobic intervention enhanced their $\mathrm{VO}_{2 \max }$ by $2.6 \pm 3.5 \mathrm{~mL} / \mathrm{min} / \mathrm{kg}[60]$ and there was an increase of $2.37 \pm 0.68 \mathrm{~mL} / \mathrm{min} / \mathrm{kg}$ for those who attended 27 weeks of an aerobic and reinforcement program [58]. Overall, randomized controlled clinical trials have shown that patients taking part in a physical activity program have better cardiopulmonary outcomes than those who do not take part [57-60]. Phase II of Hornsby's randomized study was the only one conducted on HER2+ patients treated with neoadjuvant chemotherapy (+ aerobic training) [60]. The intervention consisted in a one-to-one supervised cycle ergometry session (3 sessions/week) covering the 12 weeks of neoadjuvant chemotherapy, with progressive intensification of both duration and intensity of the exercise. There was no resistance training offered in this trial. However, cardiopulmonary function improved in the intervention group, unlike the control group, in which it decreased. According to De Luca, a supervised program (24 weeks, 2 sessions of 90 min per week, aerobic and strength training) at least six months after completion of all cancer therapies, improved $\mathrm{VO}_{2 \max }$ by about $38.8 \%$ from baseline to the end of the program [59]. One limitation of these studies was the small numbers of 
patients included $(\mathrm{N}=20)$. Studies on larger populations are required. Recently, it has been shown that

a 16-week physical activity intervention for physically inactive overweight or obese breast cancer patients after treatment improves physical fitness $(\mathrm{N}=91)$ [61]. The authors highlighted the high adherence rate $(96 \%)$ and noted that this could be linked to a reduction in the patients' barriers to physical activity. Indeed, patients were free to go to one-to-one supervised exercise sessions every day of the week from 5 am to $8 \mathrm{pm}$. Furthermore, parking and bus passes were made available in order to facilitate access to the facility.

\section{Ongoing interventional clinical trials for HER2+ breast cancer patients}

At present, only two French trials, including our own, are studying the effect of an exercise program on cardiotoxicity among HER2+ patients. CARDAPAC (NCT02433067) is a phase II, prospective, randomized, multicenter study conducted by a research team in Besançon [76]. It aims to evaluate the impact on cardiac function of aerobic exercise among HER2+ patients exclusively treated with trastuzumab. The exercising regime is individualized and consists in 45-minutes of endurance exercises (of moderate and high intensity), 3 times a week for 3 months. The program starts after the end of the chemotherapy and radiotherapy if indicated, and patients are monitored for 6 months. The primary objective of CARDAPAC is to evaluate the incidence rate of cardiotoxicity, defined as a decrease in the LVEF to less than $50 \%$ or an absolute drop in the LVEF of $10 \%$ from baseline.

Our own study, the APACAN2 (NCT02963363) trial, aims to evaluate the feasibility of home-based adapted physical activity for HER2+ breast cancer patients treated with neoadjuvant chemotherapy and anti-HER2 targeted therapy. It is a prospective, non-randomized, interventional study. The physical activity program takes place precisely during the period of the anthracycline-based chemotherapy. It comprises both aerobic and resistance exercises. The main objective of the study is to show the feasibility of a physical activity intervention conducted at home, for patients treated with neoadjuvant chemotherapy and anti-HER2 targeted therapy, in order to comply with the international recommendations defined by the WHO (i.e. at least 150 minutes of moderate-intensity aerobic physical activity or at least 75 minutes of vigorous-intensity activity or an equivalent combination of moderate-to-vigorous intensity activity throughout the week [3]). There is a lack of data concerning 
physical activity practice from the beginning of breast cancer treatment in case of neoadjuvant chemotherapy, and this study will allow the feasibility of home-based adapted physical activity to be assessed (aerobic and resistance training) for the first time in this early period of treatment.

According to the data, the need for HER2+ breast cancer patients is to increase or maintain their level of physical activity until they reach the international recommendations. It also enables their sedentary time to be reduced in order to offset treatment-induced cardiotoxicity. The intervention for this patient subgroup needs to be initiated as soon as possible in order to anticipate and prevent any cardiac events. A cardiopulmonary exercise test enables the intensity of physical activity to be adjusted according to each patient's capacities and to ensure that there is no contraindication to exercise.

It is essential to integrate aerobic exercising into the program because of the benefits on the cardiovascular system. It enables cardiopulmonary function, notably $\mathrm{VO}_{2 \max }$, to be relatively rapidly improved among breast cancer patients (Table 1). Nevertheless, muscular strength is also required because increase in muscle mass is linked to a decrease in fat mass, and thus contributes to better body composition [73]. Furthermore, De Luca et al. among breast cancer survivors showed that resistance training limited body mass gain, which is often associated with an increase in fat mass and a loss of muscle mass [59]. Indeed, adjuvant breast cancer treatments, such as endocrine therapy, are linked to weight gain mainly corresponding to fat mass gain in the abdominal region [77,78] and physical activity practice could improve these negative long term side effects.

A particularity of the physical activity program is that it can offer support in many forms to encourage practice [79-81]. For example, a pedometer can be given to patients to measure the distance that needs to be reached every week. It can even be a pedometer connected to a smartphone application. Patients could thus see their daily activity and sedentary time, or even monitor their personalized objectives and their progress. The advantage of this tool is that their sports instructor can also see their patient's physical activity and adapt the program according to the patient's physical fitness.

\section{BARRIERS AND FACILITATORS TO PRACTICE: HOW CANPHYSICAL ACTIVITY PROGRAMS BE}


The success of physical activity interventions lies in the participation of patients. There is therefore a real challenge to identify the barriers and facilitators in order to optimize adherence to a physical activity program.

\section{Barriers to exercising}

Possible barriers to practice are numerous and can be physical, psychological or even organisational. It is essential to identify these barriers so that they can be overcome for the purpose of improving physical activity practice. Some factors hindering physical activity practice have already been identified.

Barriers linked to disease or treatment side effects are among the most important. Indeed, Courneya et al. studied barriers to physical activity in a three-arm randomized trial (aerobic exercise training versus resistance exercise training versus usual care) and reported that side effects were the reason for more than $50 \%$ of missed supervised exercise sessions on offer in their trial during chemotherapy [82]. Patients mentioned mainly fatigue, nausea, and not feeling well on the day of the chemotherapy administration as barriers to physical activity, since it interfered with their ability to exercise. Nevertheless, it should be considered that before treatment initiation, patients can have comorbidities that already affect their ability to engage in physical activity [83]. Further to this, the notion of selfimage should also be considered. Changes in appearance and body image are also barriers to physical activity because patients can be wearing a wig or a prosthesis [84]. This makes the practice of certain activities more complicated, such as swimming for example, because of the close-fitting swimsuits [85]. It adds a further barrier to exercise, especially because of the embarrassment patients might feel in public. Organisational barriers are the second theme among limitations to physical activity practice. Firstly, the distance between home or the workplace and the sports facility frequently appears as a considerable limitation $[83,86-88]$. What is more, infrastructures are often located in cities, so that access is more difficult for those who live in the countryside. Nevertheless, even for patients living in the city, the risk of encountering traffic problems should also be taken into account as a barrier [86].

When the disease occurs, patients struggle to maintain a balance between work and family life and give more value to the time spent with family and/or friends than doing exercise [84]. They want to 
take responsibility for their families as they did before diagnosis, and this can also be a barrier to exercise $[88,89]$. Patients who did not have time to practice any physical activity before, find it all the more difficult after diagnosis $[90,91]$, especially as a lack of willpower is also a considerable barrier

320

321 [82,89-91]. Furthermore, being able to continue to go to work is a real need for certain patients, to fight emotional distress and to feel that they are in control. However, this requires a lot of energy and patients are often too tired to engage in a physical activity on top of everything [84]. Furthermore, it has been shown that socioeconomic status also influences physical activity. Indeed, women with a higher level of education are more likely to work full time, and alongside to have a lower moderate exercise level. Thus, employment status could interfere with leisure time and reduce the opportunity to engage in exercising [92].

The psychological aspect is another theme highlighted in certain studies [85-87,93,94]. Overprotection by the patients' entourage has been recognised as a limitation to physical exercise. Furthermore, some patients do not know that they can exercise during treatment or are afraid that it might worsen their symptoms. This raises the problem of the lack of information on physical activity that should be provided by the medical staff $[93,94]$. And although they may feel uncomfortable exercising in front of healthy people, as mentioned above, patients also report the importance of support to increase their motivation [89,92-94].

It has been shown that the more barriers there are for patients, the lower their level of physical activity $[82,95]$, and also that reducing barriers to exercise is correlated with an increase in physical activity levels. Indeed, Ottenbacher et al. showed that patients who reduced their barriers from baseline to 1 year increased their physical activity levels by 91 minutes per week [91]. Facilitating access to training sessions (flexible times, car or bus access, etc.) evidences better adherence rates [61].

\section{How can patients be encouraged to be physically active during treatment?}

Identifying barriers to physical activity provides an understanding of how to encourage patients to be physically active. First of all, receiving information about the benefits of physical activity during treatment is highly important [83]. Some studies have shown that patients who are aware of the benefits of exercise during treatment are more active than those who do not have this information [96]. 
Other studies have shown that the influence of the physician proves to be the most decisive incentive among patients to practice a physical activity: by providing reassurance on potential health issues (restoring confidence in their health, reassurance about fear of injury and fatigue), along with the physician's involvement and interest (specific request and monitoring of the patient's physical activity) $[97,98]$. All these elements point to the importance of information to patients and the training of physicians/oncologists on the effects of physical activity. Finally, a personal background of physical activity is also important, because it is easier for patients to continue a physical activity practice during treatment if they were already active before. For other patients, diagnosis appears as a trigger and a motivational factor that motivates them to take care of themselves [83].

Another key point in promoting physical activity is to personalize the program for each patient. A randomized controlled study, after a one-year follow-up, showed that patients in the tailoredintervention arm adhered better to the diet and exercise recommendations than the control group who were only given standardized diet and exercise brochures [99]. This trial underlines the importance of personalizing the intervention for each patient in order to facilitate enrolment on a training program. It is also essential to define realistic goals for each patient so as to enhance their feeling of self-efficacy $[100,101]$, especially since it has been shown that patients who are less inclined to take part in a physical activity program are also those who feel unable to carry it through [102].

Social support plays a favourable role in physical activity levels. Patients feel comfortable when exercising with other breast cancer women and developing relationships is a source of motivation $[85,86]$.

Lastly, the emergence of mobile applications and connected devices promoting diet and physical activities has upgraded the classic approach to practice. Using new technologies through applications for smartphones or other electronic devices has proved to be a motivation for patients [103]. It has been shown that a physical activity program associated with receiving weekly review emails and access to an e-counsellor for advice on exercise and physical activity is more efficient than a standard physical activity program for improving levels of physical activity among breast cancer patient survivors [104]. Furthermore, new information and communication technologies appear as a good way to establish regular patient follow-up, which is paramount during a physical activity program. 


\section{Conclusion}

As a result of the side effects of the treatment they receive, HER2+ breast cancer patients are particularly exposed to cardiac events during or after therapy. Over the years, the idea has emerged that being active during treatment could present several advantages for patients, and studies have confirmed an improvement in numerous aspects of patient condition during and after treatment (quality of life, asthenia, treatment compliance, cardiac function, etc.). Trials that have been conducted on this issue are very heterogeneous and no standard recommendations are available for HER $2+$ breast cancer patients. Nevertheless, the importance of practising aerobic exercise is obvious on account of its benefits for the heart. It is essential to facilitate adherence, in particular, so as to maintain patient motivation. The practice of physical activity should be viewed as leisure and integrated into the patient's daily life. Further studies are certainly required to determine how to integrate physical activity practice into HER2+ breast cancer patients' treatment plans. Studies on cost-effectiveness are also needed to assess the medical- and economic consequence of physical activity practice during treatment, which could promote a return to professional activity, thereby reducing the long-term costs.

\section{STATEMENTS}

\section{Acknowledgement: None}

Statement of ethics: The authors have no ethical conflicts to disclose.

Disclosure of statement: The authors have no conflicts of interest to declare.

Funding sources: Not applicable

Author contributions: AG, ET, EG, XD wrote the original draft of the paper. MD, JP, IM, CA and RT reviewed the paper and suggested draft changes. All authors have read and approved the final version of the manuscript.

\section{REFERENCES}

1 OMS | Activité physique. WHO [cited 2016 Apr 4];Available from: http://www.who.int/dietphysicalactivity/pa/fr/

2 Biswas A, Oh PI, Faulkner GE, Bajaj RR, Silver MA, Mitchell MS, et al.: Sedentary time and its association with risk for disease incidence, mortality, and hospitalization in adults: a systematic review and meta-analysis. Ann Intern Med 2015;162:123-132. 
3 WHO: Global Recommendations on Physical Activity for Health. Geneva, World Health Organization, 2010, [cited 2018 May 7].Available from:

http://www.ncbi.nlm.nih.gov/books/NBK305057/

$4 \quad$ INCa: Objectif 8 : Réduire les risques de séquelles et de second cancer - Les 17 objectifs du Plan | Institut National Du Cancer 2014 [cited 2016 May 26];Available from: http://www.ecancer.fr/Plan-cancer/Plan-cancer-2014-2019-priorites-et-objectifs/Les-17-objectifs-duPlan2/Objectif-8-Reduire-les-risques-de-sequelles-et-de-second-cancer

5 Rock CL, Doyle C, Demark-Wahnefried W, Meyerhardt J, Courneya KS, Schwartz AL, et al.: Nutrition and physical activity guidelines for cancer survivors. CA Cancer J Clin 2012;62:243274.

6 Doyle C, Kushi LH, Byers T, Courneya KS, Demark-Wahnefried W, Grant B, et al.: Nutrition and physical activity during and after cancer treatment: an American Cancer Society guide for informed choices. CA Cancer J Clin 2006;56:323-353.

7 Thivat E, Thérondel S, Lapirot O, Abrial C, Gimbergues P, Gadéa E, et al.: Weight change during chemotherapy changes the prognosis in non metastatic breast cancer for the worse. BMC Cancer 2010;10:648.

8 Gadéa É, Thivat É, Wang-Lopez Q, Viala M, Paulon R, Planchat É, et al.: [Poor prognostic value of weight change during chemotherapy in non-metastatic breast cancer patients: causes, mechanisms involved and preventive strategies]. Bull Cancer (Paris) 2013;100:865-870.

9 Mishra SI, Scherer RW, Geigle PM, Berlanstein DR, Topaloglu O, Gotay CC, et al.: Exercise interventions on health-related quality of life for cancer survivors. Cochrane Database Syst Rev 2012;CD007566.

10 Zhang X, Li Y, Liu D: Effects of exercise on the quality of life in breast cancer patients: a systematic review of randomized controlled trials. Support Care Cancer Off J Multinatl Assoc Support Care Cancer 2018; DOI: 10.1007/s00520-018-4363-2

11 Ibrahim EM, Al-Homaidh A: Physical activity and survival after breast cancer diagnosis: metaanalysis of published studies. Med Oncol 2010;28:753-765.

12 Holmes MD, Chen WY, Feskanich D, Kroenke CH, Colditz GA: Physical activity and survival after breast cancer diagnosis. JAMA 2005;293:2479-2486.

13 Blanchard CM, Courneya KS, Stein K, American Cancer Society's SCS-II: Cancer survivors' adherence to lifestyle behavior recommendations and associations with health-related quality of life: results from the American Cancer Society's SCS-II. J Clin Oncol Off J Am Soc Clin Oncol 2008;26:2198-2204.

14 Coups EJ, Ostroff JS: A population-based estimate of the prevalence of behavioral risk factors among adult cancer survivors and noncancer controls. Prev Med 2005;40:702-711.

15 Eakin EG, Youlden DR, Baade PD, Lawler SP, Reeves MM, Heyworth JS, et al.: Health behaviors of cancer survivors: data from an Australian population-based survey. Cancer Causes Control CCC 2007;18:881-894. 
16 Arem H, Moore SC, Patel A, Hartge P, Berrington de Gonzalez A, Visvanathan K, et al.: Leisure time physical activity and mortality: a detailed pooled analysis of the dose-response relationship. JAMA Intern Med 2015;175:959-967.

17 Kyu HH, Bachman VF, Alexander LT, Mumford JE, Afshin A, Estep K, et al.: Physical activity and risk of breast cancer, colon cancer, diabetes, ischemic heart disease, and ischemic stroke events: systematic review and dose-response meta-analysis for the Global Burden of Disease Study 2013. BMJ 2016;354:i3857.

Yu AF, Jones LW: Breast cancer treatment-associated cardiovascular toxicity and effects of exercise countermeasures. Cardio-Oncol Lond Engl 2016;2. DOI: 10.1186/s40959-016-0011-5

Swain SM, Whaley FS, Ewer MS: Congestive heart failure in patients treated with doxorubicin: a retrospective analysis of three trials. Cancer 2003;97:2869-2879.

Smith LA, Cornelius VR, Plummer CJ, Levitt G, Verrill M, Canney P, et al.: Cardiotoxicity of anthracycline agents for the treatment of cancer: systematic review and meta-analysis of randomised controlled trials. BMC Cancer 2010;10:337.

21 Mantarro S, Rossi M, Bonifazi M, D’Amico R, Blandizzi C, La Vecchia C, et al.: Risk of severe cardiotoxicity following treatment with trastuzumab: a meta-analysis of randomized and cohort studies of 29,000 women with breast cancer. Intern Emerg Med 2016;11:123-140.

22 Chen T, XU T, Li Y, Liang C, Chen J, Lu Y, et al.: Risk of cardiac dysfunction with trastuzumab in breast cancer patients: a meta-analysis. Cancer Treat Rev 2011;37:312-320.

23 Smith I, Procter M, Gelber RD, Guillaume S, Feyereislova A, Dowsett M, et al.: 2-year follow-up of trastuzumab after adjuvant chemotherapy in HER2-positive breast cancer: a randomised controlled trial. Lancet Lond Engl 2007;369:29-36.

24 Zamorano Jose Luis, Lancellotti Patrizio, Rodriguez Muñoz Daniel, Aboyans Victor, Asteggiano Riccardo, Galderisi Maurizio, et al.: 2016 ESC Position Paper on cancer treatments and cardiovascular toxicity developed under the auspices of the ESC Committee for Practice Guidelines. Eur J Heart Fail 2017;19:9-42.

25 Procter M, Suter TM, de Azambuja E, Dafni U, van Dooren V, Muehlbauer S, et al.: Longer-term assessment of trastuzumab-related cardiac adverse events in the Herceptin Adjuvant (HERA) trial. J Clin Oncol Off J Am Soc Clin Oncol 2010;28:3422-3428.

26 Piccart-Gebhart MJ, Procter M, Leyland-Jones B, Goldhirsch A, Untch M, Smith I, et al.: Trastuzumab after adjuvant chemotherapy in HER2-positive breast cancer. N Engl J Med 2005;353:1659-1672.

27 McArthur HL, Chia S: Cardiotoxicity of trastuzumab in clinical practice. N Engl J Med 2007;357:94-95.

28 Chen B, Peng X, Pentassuglia L, Lim CC, Sawyer DB: Molecular and cellular mechanisms of anthracycline cardiotoxicity. Cardiovasc Toxicol 2007;7:114-121.

29 Simůnek T, Stérba M, Popelová O, Adamcová M, Hrdina R, Gersl V: Anthracycline-induced cardiotoxicity: overview of studies examining the roles of oxidative stress and free cellular iron. Pharmacol Rep PR 2009;61:154-171. 
30 Wallace KB: Adriamycin-induced interference with cardiac mitochondrial calcium homeostasis. Cardiovasc Toxicol 2007;7:101-107.

31 Zhu W, Soonpaa MH, Chen H, Shen W, Payne RM, Liechty EA, et al.: Acute doxorubicin cardiotoxicity is associated with p53-induced inhibition of the mammalian target of rapamycin pathway. Circulation 2009;119:99-106.

32 Slamon DJ, Clark GM, Wong SG, Levin WJ, Ullrich A, McGuire WL: Human breast cancer: correlation of relapse and survival with amplification of the HER-2/neu oncogene. Science 1987;235:177-182.

33 Cobleigh MA, Vogel CL, Tripathy D, Robert NJ, Scholl S, Fehrenbacher L, et al.: Multinational study of the efficacy and safety of humanized anti-HER2 monoclonal antibody in women who have HER2-overexpressing metastatic breast cancer that has progressed after chemotherapy for metastatic disease. J Clin Oncol Off J Am Soc Clin Oncol 1999;17:2639-2648.

34 Baselga J, Carbonell X, Castañeda-Soto N-J, Clemens M, Green M, Harvey V, et al.: Phase II study of efficacy, safety, and pharmacokinetics of trastuzumab monotherapy administered on a 3weekly schedule. J Clin Oncol Off J Am Soc Clin Oncol 2005;23:2162-2171.

35 Slamon DJ, Leyland-Jones B, Shak S, Fuchs H, Paton V, Bajamonde A, et al.: Use of chemotherapy plus a monoclonal antibody against HER2 for metastatic breast cancer that overexpresses HER2. N Engl J Med 2001;344:783-792.

36 Marty M, Cognetti F, Maraninchi D, Snyder R, Mauriac L, Tubiana-Hulin M, et al.: Randomized phase II trial of the efficacy and safety of trastuzumab combined with docetaxel in patients with human epidermal growth factor receptor 2-positive metastatic breast cancer administered as first-line treatment: the M77001 study group. J Clin Oncol Off J Am Soc Clin Oncol 2005;23:4265-4274.

37 Cuello M, Ettenberg SA, Clark AS, Keane MM, Posner RH, Nau MM, et al.: Down-regulation of the erbB-2 receptor by trastuzumab (herceptin) enhances tumor necrosis factor-related apoptosis-inducing ligand-mediated apoptosis in breast and ovarian cancer cell lines that overexpress erbB-2. Cancer Res 2001;61:4892-4900.

38 Romond EH, Perez EA, Bryant J, Suman VJ, Geyer CE, Davidson NE, et al.: Trastuzumab plus adjuvant chemotherapy for operable HER2-positive breast cancer. N Engl J Med 2005;353:1673-1684.

39 Sengupta PP, Northfelt DW, Gentile F, Zamorano JL, Khandheria BK: Trastuzumab-induced cardiotoxicity: heart failure at the crossroads. Mayo Clin Proc 2008;83:197-203.

40 Farolfi A, Melegari E, Aquilina M, Scarpi E, Ibrahim T, Maltoni R, et al.: Trastuzumab-induced cardiotoxicity in early breast cancer patients: a retrospective study of possible risk and protective factors. Heart Br Card Soc 2013;99:634-639.

41 Fried G, Regev T, Moskovitz M: Trastuzumab-related cardiac events in the treatment of early breast cancer. Breast Cancer Res Treat 2013;142:1-7.

42 Thavendiranathan P, Abdel-Qadir H, Fischer HD, Camacho X, Amir E, Austin PC, et al.: Breast Cancer Therapy-Related Cardiac Dysfunction in Adult Women Treated in Routine Clinical Practice: A Population-Based Cohort Study. J Clin Oncol Off J Am Soc Clin Oncol 2016;34:22392246. 
43 Moja L, Tagliabue L, Balduzzi S, Parmelli E, Pistotti V, Guarneri V, et al.: Trastuzumab containing regimens for early breast cancer. Cochrane Database Syst Rev 2012;CD006243.

44 Albini A, Cesana E, Donatelli F, Cammarota R, Bucci EO, Baravelli M, et al.: Cardio-oncology in targeting the HER receptor family: the puzzle of different cardiotoxicities of HER2 inhibitors. Future Cardiol 2011;7:693-704.

45 Spector NL, Yarden Y, Smith B, Lyass L, Trusk P, Pry K, et al.: Activation of AMP-activated protein kinase by human EGF receptor 2/EGF receptor tyrosine kinase inhibitor protects cardiac cells. Proc Natl Acad Sci U S A 2007;104:10607-10612.

46 Fuller SJ, Sivarajah K, Sugden PH: ErbB receptors, their ligands, and the consequences of their activation and inhibition in the myocardium. J Mol Cell Cardiol 2008;44:831-854.

47 Zhao YY, Sawyer DR, Baliga RR, Opel DJ, Han X, Marchionni MA, et al.: Neuregulins promote survival and growth of cardiac myocytes. Persistence of ErbB2 and ErbB4 expression in neonatal and adult ventricular myocytes. J Biol Chem 1998;273:10261-10269.

48 Iwamoto R, Yamazaki S, Asakura M, Takashima S, Hasuwa H, Miyado K, et al.: Heparin-binding EGF-like growth factor and ErbB signaling is essential for heart function. Proc Natl Acad Sci U S A 2003;100:3221-3226.

49 De Keulenaer GW, Doggen K, Lemmens K: The vulnerability of the heart as a pluricellular paracrine organ: lessons from unexpected triggers of heart failure in targeted ErbB2 anticancer therapy. Circ Res 2010;106:35-46.

50 Cote GM, Sawyer DB, Chabner BA: ERBB2 inhibition and heart failure. N Engl J Med 2013;368:876.

51 Seidman A, Hudis C, Pierri MK, Shak S, Paton V, Ashby M, et al.: Cardiac dysfunction in the trastuzumab clinical trials experience. J Clin Oncol Off J Am Soc Clin Oncol 2002;20:1215-1221.

52 Dahabreh IJ, Linardou H, Siannis F, Fountzilas G, Murray S: Trastuzumab in the adjuvant treatment of early-stage breast cancer: a systematic review and meta-analysis of randomized controlled trials. The Oncologist 2008;13:620-630.

53 Bowles EJA, Wellman R, Feigelson HS, Onitilo AA, Freedman AN, Delate T, et al.: Risk of heart failure in breast cancer patients after anthracycline and trastuzumab treatment: a retrospective cohort study. J Natl Cancer Inst 2012;104:1293-1305.

54 Schneeweiss A, Chia S, Hickish T, Harvey V, Eniu A, Hegg R, et al.: Pertuzumab plus trastuzumab in combination with standard neoadjuvant anthracycline-containing and anthracycline-free chemotherapy regimens in patients with HER2-positive early breast cancer: a randomized phase II cardiac safety study (TRYPHAENA). Ann Oncol Off J Eur Soc Med Oncol 2013;24:22782284.

55 Sendur MAN, Aksoy S, Altundag K: Cardiotoxicity of novel HER2-targeted therapies. Curr Med Res Opin 2013;29:1015-1024.

56 Schneider CM, Hsieh CC, Sprod LK, Carter SD, Hayward R: Effects of supervised exercise training on cardiopulmonary function and fatigue in breast cancer survivors during and after treatment. Cancer 2007;110:918-925. 
57 Fairey AS, Courneya KS, Field CJ, Bell GJ, Jones LW, Mackey JR: Effects of exercise training on fasting insulin, insulin resistance, insulin-like growth factors, and insulin-like growth factor binding proteins in postmenopausal breast cancer survivors: a randomized controlled trial. Cancer Epidemiol Biomark Prev Publ Am Assoc Cancer Res Cosponsored Am Soc Prev Oncol 2003;12:721-727.

565

566

567

568

569

570

571

572

573

574

575

576

577

58 Cornette T, Vincent F, Mandigout S, Antonini MT, Leobon S, Labrunie A, et al.: Effects of homebased exercise training on $\mathrm{VO} 2$ in breast cancer patients under adjuvant or neoadjuvant chemotherapy (SAPA): a randomized controlled trial. Eur J Phys Rehabil Med 2016;52:223-232.

59 De Luca V, Minganti C, Borrione P, Grazioli E, Cerulli C, Guerra E, et al.: Effects of concurrent aerobic and strength training on breast cancer survivors: a pilot study. Public Health 2016;136:126-132.

60 Hornsby WE, Douglas PS, West MJ, Kenjale AA, Lane AR, Schwitzer ER, et al.: Safety and efficacy of aerobic training in operable breast cancer patients receiving neoadjuvant chemotherapy: a phase II randomized trial. Acta Oncol Stockh Swed 2014;53:65-74.

61 Dieli-Conwright CM, Courneya KS, Demark-Wahnefried W, Sami N, Lee K, Sweeney FC, et al.: Aerobic and resistance exercise improves physical fitness, bone health, and quality of life in overweight and obese breast cancer survivors: a randomized controlled trial. Breast Cancer Res BCR 2018;20:124.

62 Foucaut A-M, Berthouze-Aranda SE, Touillaud M, Kempf-Lépine A-S, Baudinet C, Meyrand R, et al.: Reduction of health risk factors through an adapted physical activity program in patients with breast cancer. Support Care Cancer Off J Multinatl Assoc Support Care Cancer 2014;22:1097-1104.

63 Kim C-J, Kang D-H, Smith BA, Landers KA: Cardiopulmonary responses and adherence to exercise in women newly diagnosed with breast cancer undergoing adjuvant therapy. Cancer Nurs 2006;29:156-165.

64 Kolden GG, Strauman TJ, Ward A, Kuta J, Woods TE, Schneider KL, et al.: A pilot study of group exercise training (GET) for women with primary breast cancer: feasibility and health benefits. Psychooncology 2002;11:447-456.

65 Leach HJ, Danyluk JM, Nishimura KC, Culos-Reed SN: Benefits of 24 versus 12 weeks of exercise and wellness programming for women undergoing treatment for breast cancer. Support Care Cancer Off J Multinatl Assoc Support Care Cancer 2016;24:4597-4606.

66 Noble M, Russell C, Kraemer L, Sharratt M: UW WELL-FIT: the impact of supervised exercise programs on physical capacity and quality of life in individuals receiving treatment for cancer. Support Care Cancer Off J Multinatl Assoc Support Care Cancer 2012;20:865-873.

67 Sturgeon KM, Ky B, Libonati JR, Schmitz KH: The effects of exercise on cardiovascular outcomes before, during, and after treatment for breast cancer. Breast Cancer Res Treat 2014;143:219226.

68 Jones LW, Haykowsky MJ, Swartz JJ, Douglas PS, Mackey JR: Early Breast Cancer Therapy and Cardiovascular Injury. J Am Coll Cardiol 2007;50:1435-1441.

69 Kavazis AN, McClung JM, Hood DA, Powers SK: Exercise induces a cardiac mitochondrial phenotype that resists apoptotic stimuli. Am J Physiol Heart Circ Physiol 2008;294:H928-935. 
70 Ascensão A, Ferreira R, Magalhães J: Exercise-induced cardioprotection--biochemical, morphological and functional evidence in whole tissue and isolated mitochondria. Int J Cardiol 2007;117:16-30.

71 Jones LW, Habel LA, Weltzien E, Castillo A, Gupta D, Kroenke CH, et al.: Exercise and Risk of Cardiovascular Events in Women With Nonmetastatic Breast Cancer. J Clin Oncol Off J Am Soc Clin Oncol 2016;34:2743-2749.

72 Haykowsky MJ, Mackey JR, Thompson RB, Jones LW, Paterson DI: Adjuvant Trastuzumab Induces Ventricular Remodeling Despite Aerobic Exercise Training. Clin Cancer Res 2009;15:4963-4967.

73 Courneya KS, Segal RJ, Mackey JR, Gelmon K, Reid RD, Friedenreich CM, et al.: Effects of aerobic and resistance exercise in breast cancer patients receiving adjuvant chemotherapy: a multicenter randomized controlled trial. J Clin Oncol Off J Am Soc Clin Oncol 2007;25:43964404.

74 Travier N, Velthuis MJ, Steins Bisschop CN, van den Buijs B, Monninkhof EM, Backx F, et al.: Effects of an 18-week exercise programme started early during breast cancer treatment: a randomised controlled trial. BMC Med 2015;13:121.

75 Courneya KS, McKenzie DC, Mackey JR, Gelmon K, Friedenreich CM, Yasui Y, et al.: Subgroup effects in a randomised trial of different types and doses of exercise during breast cancer chemotherapy. Br J Cancer 2014;111:1718-1725.

76 Jacquinot $\mathrm{Q}$, Meneveau N, Chatot M, Bonnetain F, Degano B, Bouhaddi M, et al.: A phase 2 randomized trial to evaluate the impact of a supervised exercise program on cardiotoxicity at 3 months in patients with HER2 overexpressing breast cancer undergoing adjuvant treatment by trastuzumab: design of the CARDAPAC study. BMC Cancer 2017;17:425.

77 Ginzac A, Émilie T, Marie-Ange M-R, Pascale D-L, Isabelle VP, Judith P, et al.: Weight evolution during endocrine therapy for breast cancer in postmenopausal patients: impact of initial fat mass percentage and previous adjuvant treatments. Clin Breast Cancer DOI: 10.1016/j.clbc.2018.06.010

78 Battisti S, Guida FM, Coppa F, Vaccaro DM, Santini D, Tonini G, et al.: Modification of abdominal fat distribution after aromatase inhibitor therapy in breast cancer patients visualized using 3-D computed tomography volumetry. Clin Breast Cancer 2014;14:365-370.

79 Zhu J, Ebert L, Liu X, Chan SW-C: A mobile application of breast cancer e-support program versus routine Care in the treatment of Chinese women with breast cancer undergoing chemotherapy: study protocol for a randomized controlled trial. BMC Cancer 2017;17:291.

80 Coughlin SS, Besenyi GM, Bowen D, De Leo G: Development of the Physical activity and Your Nutrition for Cancer (PYNC) smartphone app for preventing breast cancer in women. mHealth 2017;3:5.

81 Cheong IY, An SY, Cha WC, Rha MY, Kim ST, Chang DK, et al.: Efficacy of Mobile Health Care Application and Wearable Device in Improvement of Physical Performance in Colorectal Cancer Patients Undergoing Chemotherapy. Clin Colorectal Cancer 2018;17:e353-e362. 
82 Courneya KS, McKenzie DC, Reid RD, Mackey JR, Gelmon K, Friedenreich CM, et al.: Barriers to supervised exercise training in a randomized controlled trial of breast cancer patients receiving chemotherapy. Ann Behav Med Publ Soc Behav Med 2008;35:116-122.

83 Henriksson A, Arving C, Johansson B, Igelström H, Nordin K: Perceived barriers to and facilitators of being physically active during adjuvant cancer treatment. Patient Educ Couns 2016;99:1220-1226.

84 Husebø AML, Karlsen B, Allan H, Søreide JA, Bru E: Factors perceived to influence exercise adherence in women with breast cancer participating in an exercise programme during

85 Emslie C, Whyte F, Campbell A, Mutrie N, Lee L, Ritchie D, et al.: “I wouldn't have been

86 Wurz A, St-Aubin A, Brunet J: Breast cancer survivors' barriers and motives for participating in a group-based physical activity program offered in the community. Support Care Cancer Off J Multinatl Assoc Support Care Cancer 2015;23:2407-2416.

87 Hefferon K, Murphy H, McLeod J, Mutrie N, Campbell A: Understanding barriers to exercise implementation 5-year post-breast cancer diagnosis: a large-scale qualitative study. Health Educ Res 2013;28:843-856.

88 Loh SY, Lee SY, Quek KF, Murray L: Barriers to participation in a randomized controlled trial of Qigong exercises amongst cancer survivors: lessons learnt. Asian Pac J Cancer Prev APJCP 2012;13:6337-6342.

89 Charlier C, Van Hoof E, Pauwels E, Lechner L, Spittaels H, De Bourdeaudhuij I: The contribution of general and cancer-related variables in explaining physical activity in a breast cancer population 3 weeks to 6 months post-treatment. Psychooncology 2013;22:203-211.

90 Loh SY, Chew S-L, Lee S-Y: Barriers to exercise: perspectives from multiethnic cancer survivors in Malaysia. Asian Pac J Cancer Prev APJCP 2011;12:1483-1488.

91 Ottenbacher AJ, Day RS, Taylor WC, Sharma SV, Sloane R, Snyder DC, et al.: Exercise among breast and prostate cancer survivors--what are their barriers? J Cancer Surviv Res Pract 2011;5:413-419.

92 Steinhilper L, Geyer S, Sperlich S: Health behavior change among breast cancer patients. Int J Public Health 2013;58:603-613.

93 Rogers LQ, Matevey C, Hopkins-Price P, Shah P, Dunnington G, Courneya KS: Exploring social cognitive theory constructs for promoting exercise among breast cancer patients. Cancer Nurs 2004;27:462-473.

94 Browall M, Mijwel S, Rundqvist $\mathrm{H}$, Wengström Y: Physical Activity During and After Adjuvant Treatment for Breast Cancer: An Integrative Review of Women's Experiences. Integr Cancer Ther 2018;17:16-30.

95 Perna FM, Craft L, Carver CS, Antoni MH: Negative affect and barriers to exercise among early stage breast cancer patients. Health Psychol Off J Div Health Psychol Am Psychol Assoc 2008;27:275-279. 
96 Jones LW, Courneya KS, Fairey AS, Mackey JR: Effects of an oncologist's recommendation to exercise on self-reported exercise behavior in newly diagnosed breast cancer survivors: a single-blind, randomized controlled trial. Ann Behav Med Publ Soc Behav Med 2004;28:105113.

97 Lanhers C, Duclos M, Guttmann A, Coudeyre E, Pereira B, Ouchchane L: General Practitioners' Barriers to Prescribe Physical Activity: The Dark Side of the Cluster Effects on the Physical Activity of Their Type 2 Diabetes Patients. PloS One 2015;10:e0140429.

98 Duclos M, Dejager S, Postel-Vinay N, di Nicola S, Quéré S, Fiquet B: Physical activity in patients with type 2 diabetes and hypertension--insights into motivations and barriers from the MOBILE study. Vasc Health Risk Manag 2015;11:361-371.

99 Demark-Wahnefried W, Clipp EC, Lipkus IM, Lobach D, Snyder DC, Sloane R, et al.: Main Outcomes of the FRESH START Trial: A Sequentially Tailored, Diet and Exercise Mailed Print Intervention Among Breast and Prostate Cancer Survivors. J Clin Oncol 2007;25:2709-2718.

100 Pinto BM, Frierson GM, Rabin C, Trunzo JJ, Marcus BH: Home-based physical activity intervention for breast cancer patients. J Clin Oncol Off J Am Soc Clin Oncol 2005;23:35773587.

101 Demark-Wahnefried W, Morey MC, Clipp EC, Pieper CF, Snyder DC, Sloane R, et al.: Leading the Way in Exercise and Diet (Project LEAD): intervening to improve function among older breast and prostate cancer survivors. Control Clin Trials 2003;24:206-223.

102 Rabin C, Simpson N, Morrow K, Pinto B: Behavioral and psychosocial program needs of young adult cancer survivors. Qual Health Res 2011;21:796-806.

103 Goode AD, Lawler SP, Brakenridge CL, Reeves MM, Eakin EG: Telephone, print, and Web-based interventions for physical activity, diet, and weight control among cancer survivors: a systematic review. J Cancer Surviv Res Pract 2015;9:660-682.

104 Hatchett A, Hallam JS, Ford MA: Evaluation of a social cognitive theory-based email intervention designed to influence the physical activity of survivors of breast cancer. Psychooncology 2013;22:829-836.

\section{FIGURE LEGENDS}

Table 1: Physical activity interventions reporting cardiopulmonary outcomes among breast cancer patients during and after treatment

Adj: Adjuvant; AET: aerobic exercise training; CT: chemotherapy; Ctrl: Control; $H R_{\max }$ : maximum heart rate; HT: Hormone therapy; NA: Not applicable; NACT: Neoadjuvant chemotherapy; ND: Not done; RCT: Radiochemotherapy; RET: Resistance exercise training; RM: repetition maximum; RPE: Rate of perceived exertion; $R T$ : Radiotherapy; UC: usual care; $V O_{2 \max }$ : maximum peak oxygen consumption 


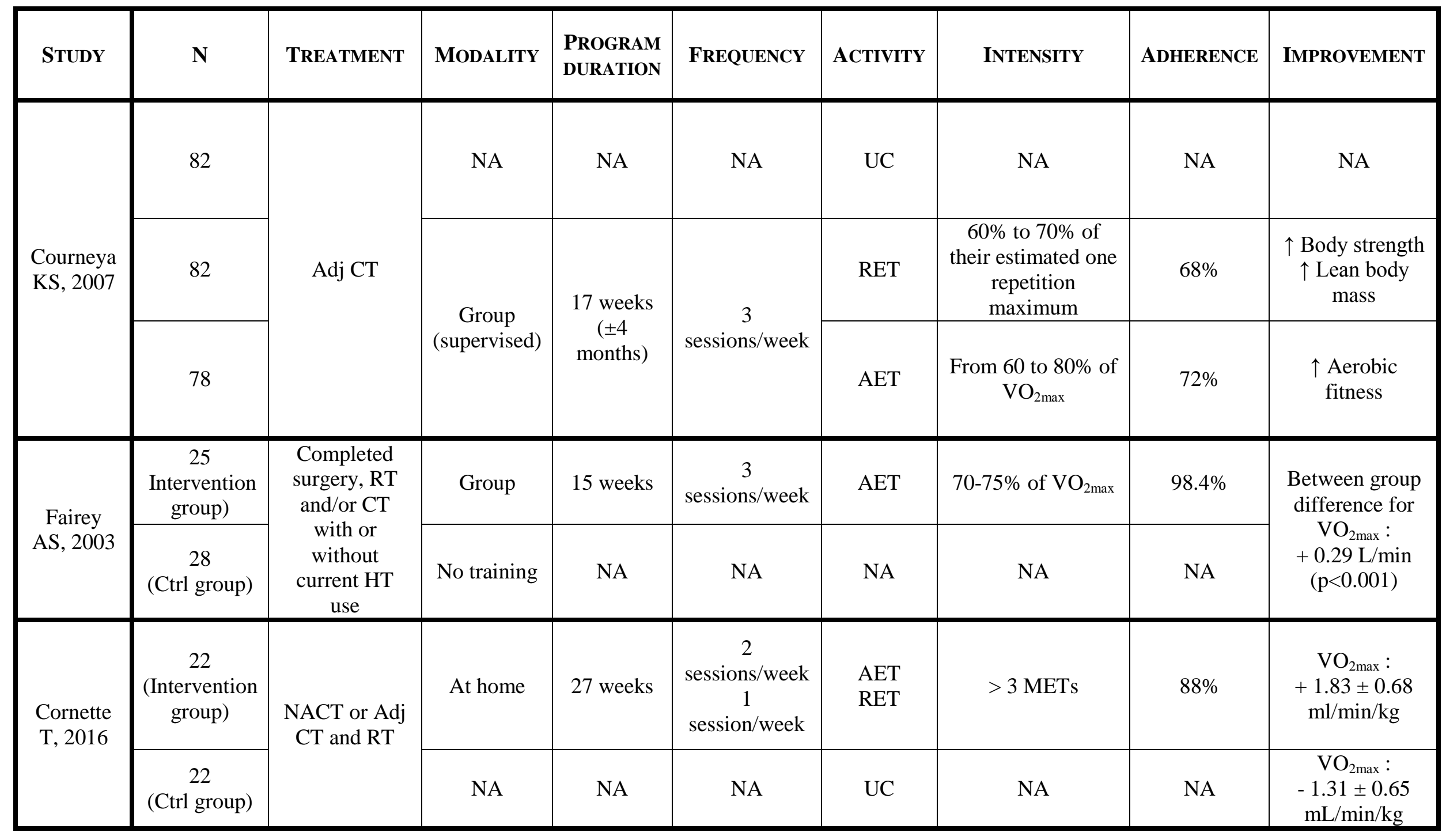




\begin{tabular}{|c|c|c|c|c|c|c|c|c|c|}
\hline \multirow[t]{2}{*}{$\begin{array}{l}\text { De Luca } \\
\text { V, } 2016\end{array}$} & $\begin{array}{c}10 \\
\text { (Intervention } \\
\text { group) }\end{array}$ & \multirow{2}{*}{$\begin{array}{l}\text { Surgery }+ \text { all } \\
\text { cancer } \\
\text { therapies } \\
\text { completed at } \\
\text { least } 6 \text { months } \\
\text { before }\end{array}$} & $\begin{array}{c}\text { Group } \\
\text { (supervised) }\end{array}$ & 24 weeks & $\begin{array}{c}2 \\
\text { sessions/week }\end{array}$ & $\begin{array}{l}\text { AET } \\
\text { RET }\end{array}$ & $\begin{array}{l}70 \% \text { to } 80 \% \text { of } \\
\text { estimated } \mathrm{HR}_{\max } \\
\text { A load of } 40 \% \text { to } \\
60 \% \text { of estimated } \\
1 \mathrm{RM}\end{array}$ & ND & $\begin{array}{c}\uparrow \mathrm{Vo}_{2 \max } \\
+38.8 \% \\
\text { between } \\
\text { baseline and end } \\
\text { of intervention }\end{array}$ \\
\hline & $\begin{array}{c}10 \\
\text { (Ctrl group) }\end{array}$ & & NA & NA & NA & NA & NA & NA & $\begin{array}{l}\text { No significant } \\
\text { change }\end{array}$ \\
\hline \multirow{2}{*}{$\begin{array}{l}\text { Hornsby, } \\
2014\end{array}$} & $\begin{array}{c}10 \\
\text { (Intervention } \\
\text { group) }\end{array}$ & NACT & $\begin{array}{l}\text { One-to-one } \\
\text { supervised } \\
\text { sessions }\end{array}$ & 12 weeks & $\begin{array}{c}2 \text { to } 3 \\
\text { sessions/week }\end{array}$ & AET & $\begin{array}{l}\text { Moderate to high } \\
\text { intensity }\end{array}$ & $66 \%$ & $\begin{array}{c}\mathrm{VO}_{2 \max }: \\
+2.6 \pm 3.5 \\
\mathrm{~mL} / \mathrm{min} / \mathrm{kg}\end{array}$ \\
\hline & $\begin{array}{c}10 \\
\text { (Ctrl group) }\end{array}$ & NA & NA & NA & NA & UC & NA & NZ & $\begin{array}{c}\mathrm{VO}_{2 \max }: \\
-1.5 \pm 2.2 \\
\mathrm{~mL} / \mathrm{min} / \mathrm{kg}\end{array}$ \\
\hline \multirow[t]{2}{*}{$\begin{array}{l}\text { Travier, } \\
2015\end{array}$} & $\begin{array}{c}102 \\
\text { (Intervention } \\
\text { group) }\end{array}$ & \multirow[t]{2}{*}{ Adj CT } & Group & 18 weeks & $\begin{array}{c}2 \\
\text { sessions/week }\end{array}$ & $\begin{array}{l}\text { AET } \\
\text { RET }\end{array}$ & $\begin{array}{l}\text { Based on the heart } \\
\text { rate at the } \\
\text { ventilatory } \\
\text { threshold as } \\
\text { determined during } \\
\text { baseline } \\
\text { cardiopulmonary } \\
\text { exercise test }\end{array}$ & $83 \%$ & $\begin{array}{c}\mathrm{VO}_{2 \max }: \\
-0.7 \mathrm{~mL} / \mathrm{min} / \mathrm{kg}\end{array}$ \\
\hline & $\begin{array}{c}102 \\
\text { (Ctrl group) }\end{array}$ & & NA & NA & NA & $\mathrm{UC}$ & NA & NA & NA \\
\hline $\begin{array}{c}\text { Dieli- } \\
\text { Conwright } \\
\text { CM, } 2018\end{array}$ & $\begin{array}{c}46 \\
\text { (Intervention } \\
\text { group) }\end{array}$ & $\begin{array}{c}<6 \text { months } \\
\text { post-treatment } \\
\text { (chemo or } \\
\text { radiotherapy) }\end{array}$ & $\begin{array}{l}\text { One-to-one } \\
\text { supervised } \\
\text { sessions }\end{array}$ & 16 weeks & $\begin{array}{c}3 \\
\text { sessions/week } \\
\text { (2 AET+RET } \\
\text { and 1 AET) }\end{array}$ & $\begin{array}{l}\text { AET } \\
\text { RET }\end{array}$ & $\begin{array}{c}\text { Moderate-vigorous } \\
\text { intensity }\end{array}$ & $96 \%$ & $\begin{array}{c}\uparrow \mathrm{Vo}_{2 \max } \\
\downarrow \text { Resting heart } \\
\text { rate }\end{array}$ \\
\hline
\end{tabular}




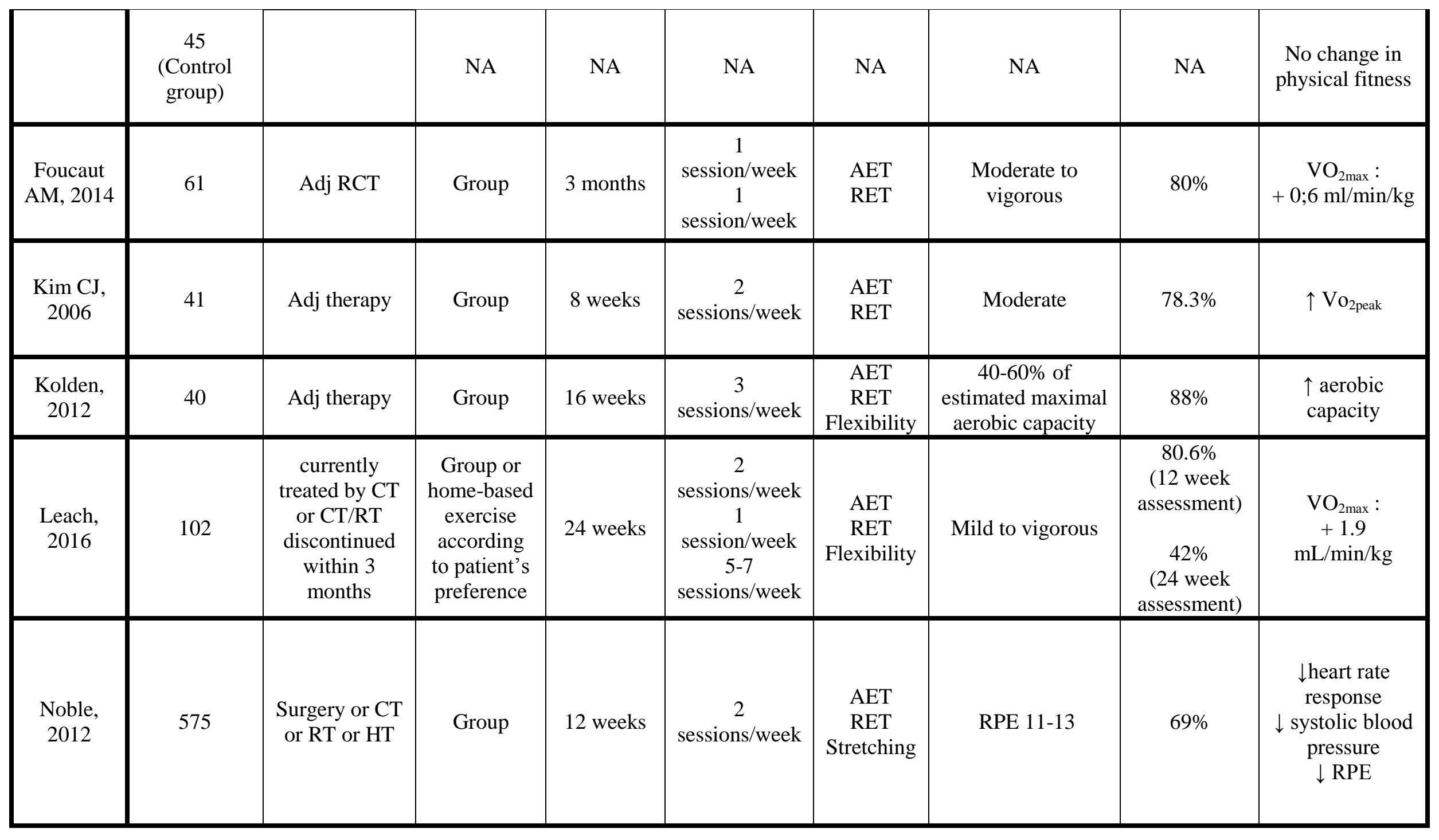

